\title{
Syphilitic hepatitis: a case report and review of the literature
}

\author{
Jiaofeng Huang ${ }^{1}$, Su Lin ${ }^{1}$, Mingfang Wang ${ }^{1}$, Bo Wan² and Yueyong Zhu ${ }^{1 *}$ (D)
}

\begin{abstract}
Background: Syphilis is a common disease that has been researched and focused on for many years, however, syphilitic hepatitis has not been well-recognized. We report this case of syphilitic hepatitis with intrahepatic cholestasis and liver granulomas to make a deeper impression.

Case presentation: A 47-year-old male was admitted with jaundice and rashes. The laboratory examination showed abnormal liver enzymes with significant increases in ALP and GGT but mild increases in ALT and AST. His HBV surface antigen was weakly positive, with negative HIV antibody, HCV antibody, and undetectable HBV DNA. The rapid plasma reagin test and the Treponema pallidum particle assay tests for Syphilis were both positive. Abdominal ultrasonography and magnetic resonance cholangiopancreatography revealed the normal biliary tract, liver, and spleen. The liver pathological examination showed cholangiocyte inflammation and micro-granulomas with coagulation necrosis. After 2 months of benzathine penicillin treatment, his liver enzyme decreased rapidly and remained normal after 1-year of follow-up.
\end{abstract}

Conclusions: Increased liver enzymes, intrahepatic cholestasis and liver granulomas with well-response to antibiotics may provide clues for the diagnosis of syphilitic hepatitis.

Keywords: Syphilis, Hepatitis, Rashes, Enzymes, Infection

\section{Background}

Syphilis is a multi-systemic disease caused by spirochete Treponema pallidum. Liver is one of the organs that can be affected [1]. Congenital syphilitic hepatitis is more common and easily recognized for its typical clinical features, while acquired syphilitic hepatitis in adults were rarely reported. Here we present a clinical case of syphilitic hepatitis whose diagnosis has been confirmed by the pathology of liver biopsy.

\section{Case presentation}

A 47-year-old man was hospitalized because of jaundice and rashes. He developed jaundice 2 weeks prior to admission. He had no fever, fatigue, anorexia, abdominal pain, or waist pain. The laboratory examinations in local hospital revealed an alanine aminotransferase (ALT) of $359 \mathrm{U} / \mathrm{L}$, an aspartate aminotransferase (AST) of $161 \mathrm{U} / \mathrm{L}$,

\footnotetext{
* Correspondence: zhuyueyong@fjmu.edu.cn

1Department of Liver Research Center, the First Affiliated Hospital of Fujian Medical University, No. 20, Chazhong Road, Taijiang District, Fuzhou 350001, Fujian, China

Full list of author information is available at the end of the article
}

an alkaline phosphatase (ALP) of $580 \mathrm{U} / \mathrm{L}$, a gammaglutamyl transpeptidase (GGT) of $883 \mathrm{U} / \mathrm{L}$ and a total bilirubin (TBIL) of $75.1 u \mathrm{~mol} / \mathrm{L}$. He received a liver protective medication (diammonium glycyrrhizinate), but jaundice did not improve. On the third day of diammonium glycyrrhizinate treatment, multiple non-itchy rashes appeared all over his body, which remained after the withdrawal of diammonium glycyrrhizinate and the application of antiallergic agents. In addition, his ALP and GGT increased to 853 and $1012 \mathrm{U} / \mathrm{L}$ in the fifth day. He was then transferred to our hospital. He denied any chronic diseases, drug administration, alcohol consumption or venereal exposure. Physical examination showed the temperature of $36.0^{\circ} \mathrm{C}$, the blood pressure of $108 / 75 \mathrm{mmHg}$, the heart rate of 77 times/min and the breath rate of 18 times/min. His skin and sclera were mildly yellowish. No hepatomegaly, splenomegaly or ascites was found. Non-itchy macular rashes measuring 0.5 to $2 \mathrm{~cm}$ were observed all over his body, including some on the soles and palms (Fig. 1a and b). No genital or buccal lesions were found. Biochemical examinations in our hospital revealed a weakly positive in hepatitis $B$ surface antigen 

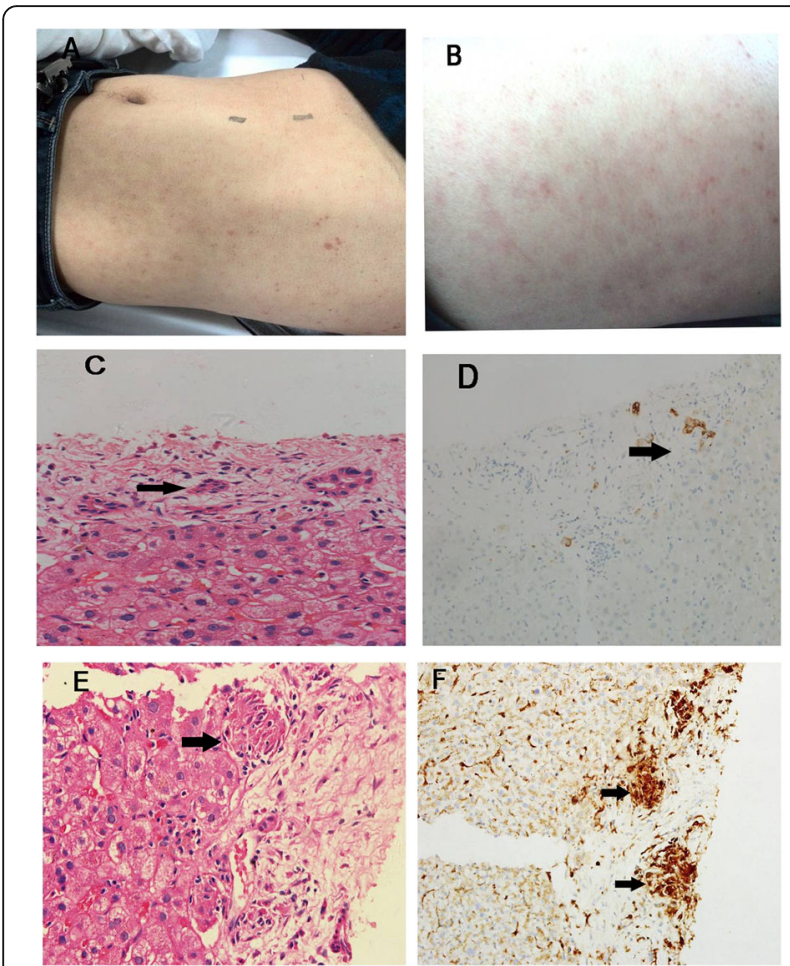

Fig. 1 Patient's body appearance and histological findings. a multiple erythematous macules and hyperpigmentation on the back; b, multiple erythematous macules and hyperpigmentation over the belly; c, HE staining shows bile duct epithelial cell injury, atrophy cholangiocyte, and portal tract inflammation $(\times 400)$; d, CK7 staining of cholangiocyte reveals atrophy cholangiocyte and bile duct lesion ( $\times 100)$; e, HE staining shows granulomas $(\times 400)$; f, CD68 staining of macrophagocyte shows granulomas $(\times 100)$. Black arrows indicate lesions

(HBsAg). His hepatitis B surface antibody, hepatitis B extracellular antigen ( $\mathrm{HBeAg}$ ) were both negative and his hepatitis B virus DNA was undetectable $(<500 \mathrm{IU} / \mathrm{ml})$. The other laboratory tests including Hepatitis A virus, Hepatitis $\mathrm{C}$ virus, Hepatitis E virus, human immunodeficiency virus, Epstein-Barr virus, cytomegalovirus, and other autoantibodies were all negative. Abdominal ultrasonography and magnetic resonance cholangiopancreatography revealed the normal biliary tract, liver, and spleen. He underwent liver biopsy and the results revealed granulomatous hepatitis with stage 2 inflammation and stage 1 fibrosis (Fig. 1c, d, e, and f). Mild hepatic lobule inflammation and plasma cells infiltrating were found in the portal area. In addition, micro-granulomas with coagulation necrosis were noticed in the portal area. Immunohistochemistry examination showed a weakly staining of HBsAg and HBcAg. He received a following test of syphilis. The rapid plasma reagin test (RPR) was positive (1,32 titer), and the Treponema pallidum particle assay (TPPA) test was 1:38, which confirmed the diagnosis of syphilis. The patient was then given intramuscular benzathine penicillin treatment at a dose of 2.4 million units per week for successive 2 months. No anti-HBV drug was given. The liver enzymes decreased rapidly after penicillin treatment and finally returned to normal level after 2 months of treatment. The follow-up showed that the liver function kept normal and HBV DNA was still undetected after 1-year.

\section{Discussion and conclusions}

Liver injury is often caused by hepatic pathogens infection, while, non-hepatotropic pathogens, such as Toxoplasma gondii, Salmonella, Leishmaniasis and Tuberculosis are able to cause the liver injury $[2,3]$. Syphilis is one of the non-hepatotropic pathogens that cause unidentified hepatitis. Syphilitic hepatitis was first described by Harn in 1943 [4]. In 2004, Mullick [5] proposed the diagnostic criteria of syphilitic hepatitis, which includes:(1) abnormal liver enzyme levels; (2) serological evidence for syphilis; (3) exclusion of other causes of liver diseases; (4) liver enzyme levels returning to normal after appropriate antimicrobial therapy. In this case, the patient met all of the above diagnostic criteria.

The clinical manifestations of syphilitic hepatitis in adults tend to be nonspecific and protean [1]. Though rashes and icterus are observed in the majority of patients. The rashes of syphilis often present as non-pruritis multiple erythematous and nonconfluent maculopapular lesions, concentrating in trunk, palms, and soles $[6,7]$. Other common symptoms include low-grade fever, abdominal pain, phallodynia, sore throat, headache, weight loss, arthralgia or myodynia, splenomegaly, lymphadenopathy, and uveitis $[1,8,9]$.

The histological features of syphilitic hepatitis can include bile duct inflammatory infiltration, which may contribute to the elevated ALP and GGT levels in biochemistry tests [1, 7]. Hepatic granulomas are another characteristic of syphilitic hepatitis [3]. Our case presented the typical intrahepatic bile duct inflammation and granuloma, which is consistent with the previously reported cases [9]. In theory, the spirochetes could be identified in liver tissue by immunohistochemical staining or a Warthin-Starry stain [10], however, it was rarely reported in cases published.

Penicillin is the first-line treatment of syphilis and the response to antimicrobial therapy is regarded as one of the diagnostic criteria of syphilitic hepatitis [5]. In this case, standard therapy was given where significant improvement was afterward achieved. These further confirmed the diagnosis of syphilitic hepatitis. The JarischHerxheimer reaction (JHR) is a severe immunological phenomenon easily seen in patients during penicillin therapy, and it mainly manifests as short-term symptoms such as fever, headache, myalgias, chills, even a sudden drop of body temperature [11]. Fortunately, JHR did not occur in our patient. According to previous reports, patients who 
had JHR can also achieve therapeutic effects through dose adjustment or the replacement of antibiotics [12].

In conclusion, there are no specific symptoms for syphilitic hepatitis. Elevated liver enzymes, especially for ALP and GGT, are common in patients. Bile duct inflammation or granuloma formation in hepatic pathology, as well as the response to antibiotic therapy, can also provide some clues for the diagnosis of syphilitic hepatitis.

\section{Abbreviations \\ ALP: Alkaline phosphatase; ALT: Alanine transaminase; AST: Aspartate aminotransferase; GGT: Gamma-glutamyl transpeptidase; HBV: Hepatitis B virus; HCV: Hepatitis C virus; HIV: Human immunodeficiency virus; JHR: Jarisch-Herxheimer reaction; RPR: Apid plasma reagin test; \\ TPPA: Treponema pallidum particle assay}

\section{Acknowledgments}

Not Applicable.

\section{Authors' contributions}

HJF did the data collection and wrote the primary draft. LS did the study design. WMF and WB were involved in manuscript preparation. LS and ZYY contributed to reporting edits and the idea for the Clinical Picture. All authors have read and approved the manuscript in its current state.

\section{Funding}

This work was supported by the Medical Project of Fujian Province (2016-CX33), Fujian Province Health Youth Research Project (2019-1-37) and Fujian Medical University Sailing Fund Project (2018QH1047). The funders had no role in study design, $\mathrm{d}$ conduct and outcome of the manuscript. No additional external funding was received for this study.

\section{Availability of data and materials}

The datasets supporting the conclusions of this article are included in the article

\section{Ethics approval and consent to participate}

Not applicable.

\section{Consent for publication}

Written informed consent for publication of their clinical details and/or clinical images was obtained from the patient.

\section{Competing interests}

The authors declare that they have no competing interests.

\section{Author details}

'Department of Liver Research Center, the First Affiliated Hospital of Fujian Medical University, No. 20, Chazhong Road, Taijiang District, Fuzhou 350001 Fujian, China. ${ }^{2}$ Faculty of Life Sciences and Medicine, King's College London, London SE1 1UL, UK.

Received: 26 March 2019 Accepted: 7 November 2019

Published online: 19 November 2019

\section{References}

1. Huang J, Lin S, Wan B, Zhu Y. A systematic literature review of syphilitic hepatitis in adults. J Clin Transl Hepatol. 2018;6(3):306-9.

2. Huang J, Zhang H, Liu S, Wang M, Wan B, Velani B, et al. Is toxoplasma gondii infection correlated with nonalcoholic fatty liver disease?- a population-based study. BMC Infect Dis. 2018;18(1):629.

3. Lamps LW. Hepatic granulomas: a review with emphasis on infectious causes. Arch Pathol Lab Med. 2015;139(7):867-75.

4. Harn RD. Syphilis of the liver. Am J Syph. 1943:27:529-62.

5. Mullick CJ, Liappis AP, Benator DA, Roberts AD, Parenti DM, Simon GL. Syphilitic hepatitis in HIV-infected patients: a report of 7 cases and review of the literature. Clin Infect Dis. 2004;39(10):e100-5.
6. Rubio-Tapia A, Hujoel IA, Smyrk TC, Poterucha JJ. Emerging secondary syphilis presenting as syphilitic hepatitis. Hepatology. 2016;65(6):2113-5.

7. Aggarwal SK, Radhakrishnan S. Syphilitic hepatitis: look for raised alkaline phosphatase level. Med J Armed Forces India. 2016;72(2):192-3.

8. Khambaty M, Singal AG, Gopal P. Spirochetes as an almost forgotten cause of hepatitis. Clin Gastroenterol Hepatol. 2015;13(2):A21-2.

9. Solari PR, Jones C, Wallace MR. Hepatic lesions with secondary syphilis in an HIV-infected patient. Case Rep Med. 2014;2014:604794.

10. Kim GH, Kim BU, Lee JH, Choi YH, Chae HB, Park SM, et al. Cholestatic hepatitis and thrombocytosis in a secondary syphilis patient. J Korean Med Sci. 2010;25(11):1661-4.

11. Butler T. The Jarisch-Herxheimer reaction after antibiotic treatment of Spirochetal infections: a review of recent cases and our understanding of pathogenesis. Am J Trop Med Hyg. 2017;96(1):46-52.

12. Adachi E, Koibuchi T, Okame M, Sato H, Imai K, Shimizu S, et al. Case of secondary syphilis presenting with unusual complications: syphilitic proctitis, gastritis, and hepatitis. J Clin Microbiol. 2011;49(12):4394-6.

\section{Publisher's Note}

Springer Nature remains neutral with regard to jurisdictional claims in published maps and institutional affiliations.

\section{Ready to submit your research? Choose BMC and benefit from:}

- fast, convenient online submission

- thorough peer review by experienced researchers in your field

- rapid publication on acceptance

- support for research data, including large and complex data types

- gold Open Access which fosters wider collaboration and increased citations

- maximum visibility for your research: over $100 \mathrm{M}$ website views per year

At BMC, research is always in progress.

Learn more biomedcentral.com/submissions 